\title{
ANÁLISE DE VIABILIDADE DE PRODUÇÃO DE COBERTURA ECOLÓGICA A PARTIR DE RESÍDUOS SÓLIDOS
}

\section{ANALYSIS OF THE FEASIBILITY OF PRODUCTION OF ECOLOGICAL COVERAGE FROM SOLID WASTE}

MÁRCIO ARAÚJO DE SOUZA, M.SC. | UNISUAM

LUCIO FÁBIO CASSIANO NASCIMENTO, Dr. | UNISUAM

KÁTIA ELIANE SANTOS AVELAR, Dra. | UNISUAM

\begin{abstract}
RESUMO
Este estudo versa sobre a viabilidade de aproveitamento de fibras de coco e resíduos de polietileno (PEAD) para a produção de telhas em camadas para a construção civil. Esses resíduos têm demonstrado resultados consideráveis quanto a sua utilização na construção civil, possibilitando a produção de materiais de construção ecológica. Trata-se de uma revisão de literatura construída com base em textos científicos publicados em base de dados como, Scielo, Google Acadêmico e periódicos da Capes, selecionados entre os anos de 1997 a 2019. Além disso, foram considerados também alguns boletins técnicos de indústrias nacionais. Deste modo, realizou-se um levantamento comparativo dos dados obtidos para a associação desses resíduos incluindo a preocupação com os impactos ambientais relacionados ao processo de conformação das fibras, destacando o uso de adesivos bioresinosos. Portanto, foi possível conhecer além dos parâmetros de associação, também os processos de produção de compósitos e de refusão do PEAD podendo ser aplicados à produção de materiais de construção como, por exemplo, telhas termoacústicas.
\end{abstract}

PALAVRAS CHAVE: resíduos de PEAD; fibras de coco; adesivo de tanino; telha ecológica; produto sustentável.

\begin{abstract}
This study deals with the feasibility of using coconut fibers and polyethylene residues (HDPE) for production of layered tiles for civil construction. These residues have shown considerable results regarding their use in civil construction, enabling the production of environmentally friendly construction materials. This is a literature review based on scientific texts published in databases such as Scielo, Google Scholar and Capes journals, selected from 1997 to 2019. In addition, some technical bulletins from industries were also considered nationals. In this way, a comparative survey of the data obtained for the association of these residues was carried out, including the concern of the environmental impacts related to the fiber forming process, highlighting the use of bioresinous adhesives. Therefore, it was possible to know, in addition to the association parameters, also the HDPE composite and remelting production processes, which can be applied to the production of construction materials such as, for example, thermoacoustic tiles.
\end{abstract}

KEY WORDS: HDPE waste; coconut fibers; tannin adhesive; ecological tile; sustainable product. 


\section{INTRODUÇÃO}

O atual padrão de consumo da sociedade estabelece uma relação de substituição de bens sem que efetivamente o produto tenha completado o seu ciclo de vida, impondo um verdadeiro processo de obsolescência planejada que nos tempos atuais, obrigatoriamente deve estar dentro dos limites da sustentabilidade. Tal processo pode ser definido como um conceito em que as mercadorias são fabricadas com um tempo útil predeterminado, com o intuito de que se tornem rapidamente obsoletas, aumentando o consumo e a economia (CARNEIRO, 2018).

Neste estudo, propõe-se o estímulo de produtos "verdes" e reciclados, favorecendo a obsolescência dos produtos não sustentáveis, fortemente utilizados na construção civil. Vale ressaltar que, diferentemente de produtos eletrônicos ou de utensílios triviais ao dia-a-dia, os produtos da construção civil tendem a ser substituídos com menor frequência, pois devem ser ofertados no mercado de modo que ofereçam segurança ao usuário dentro das normas vigentes.

Objetivou-se aqui levantar os parâmetros físico-químicos para averiguação da viabilidade técnica de produção de um material de construção. Nesse caso o material idealizado no estudo é uma telha termoacústica em camadas, uma de compósito de fibras de coco e duas de membranas de PEAD. Visa-se futuramente com a produção desse material, ofertar no mercado um modelo alternativo aos modelos convencionais, vindo de resíduos, possivelmente com menor custo de fabricação.

Nesse sentido, a presente revisão foi organizada em seis momentos importantes, destacando-se:

a) no primeiro o aproveitamento de resíduos sólidos no Brasil e sua legislação vigente;

b) no segundo uma breve descrição sobre materiais compósitos;

c) no terceiro os dados relativos à fibra de coco (material de reforço);

d) no quarto um levantamento sobre os adesivos e bioadesivos compatíveis com as fibras de coco para a produção de compósitos (matrizes);

e) no quinto os dados dos resíduos de estudo, o PEAD;

f) no sexto um resumo comparativo dos parâmetros físico-químicos dos materiais: fibras de coco; bioadesivo e resíduo de PEAD.

\section{RESÍDUOS SÓLIDOS}

Diversas iniciativas pelo país e no mundo têm sido realizadas com o propósito de reutilização dos resíduos sólidos orgânicos aproveitados desde a geração de energia à produção de diferentes produtos. Na grande maioria dos casos, os resíduos não são tratados e vêm sendo dispostos inadequadamente no ambiente, muitas vezes, contaminação o solo, a água, entre outros impactos negativos. Infelizmente ainda existem poucas alternativas para a utilização dos resíduos vegetais produzidos no Brasil. Esses resíduos poderiam ser utilizados como matéria-prima gerando renda e trabalho e promovendo cidadania (DA SILVA ET AL., 2018); (SILVA et al., 2019).

A Lei Federal 12.305/2010 institui que, somente os resíduos não recicláveis poderão ser enviados aos aterros, porém esta realidade ainda se encontra distante do ideal. Nesse contexto, a construção civil pode e deve, cada vez mais, contribuir com a Lei se tornar mais sustentável.

O uso dos resíduos relaciona-se com a sua reciclagem. É necessário analisá-lo sob os aspectos relacionados à sua origem, para que se possa avaliar a viabilidade de sua utilização. Para isso, o Centro Nacional de Referência em biomassa (CENBIO) classifica os resíduos em industriais, rurais e urbanos. Além do conhecimento sobre as implicações físicas, químicas e biológicas dos resíduos no meio ambiente, é necessário ter conhecimento quanto aos aspectos legais do uso de resíduos, diretamente ligado à conservação ambiental (DA SILVA et al., 2018; PEREIRA, 2019).

Em acordo com os autores do parágrafo anterior, um resumo da Política Nacional de Resíduos Sólidos, pode ser visto sob a forma da Lei $n^{\circ} 12.305 / 2010$, que em seu Capítulo II, nos Artigos $6^{\circ}$ e $7^{\circ}$ dispõe sobre:

[...] Art.6 - São princípios da Política Nacional de Resíduos Sólidos:

[...] VIII - refere-se ao reconhecimento do resíduo sólido reutilizável e reciclável como um bem econômico e de valor social, gerador de trabaIho e renda e promotor de cidadania.

[...] Art. 70 - São objetivos da Política Nacional de Resíduos Sólidos:

[...] $\mathrm{VI}$ - incentivo à indústria da reciclagem, tendo em vista fomentar o uso de matérias-primas e insumos derivados de materiais recicláveis e reciclados (BRASIL, 2010, p. 86).

Portanto, a destinação inadequada os resíduos, traz prejuízos ambientais. Além disso, constituiu uma atividade ilegal, sujeita às penalidades impostas por lei e destaca que os órgãos ambientais devem ser consultados, por apresentarem regulamentação própria quanto à disposição de resíduos (PEREIRA, 2019).

\section{MATERIAIS COMPÓSITOS}

São estruturas constituídas por dois ou mais materiais, formando outro material que se difere nas propriedades dos materiais de origem quando analisados isoladamente. 
Basicamente um é um material produzido pela fase de reforço que tem como principais funções suportar o esforço aplicado ao material proporcionando rigidez, resistência, estabilidade térmica e, também, outras propriedades estruturais ligados por um tipo de matriz. Na figura 1 tem-se uma ilustração da formação de um material compósito (KOTIK, 2019).

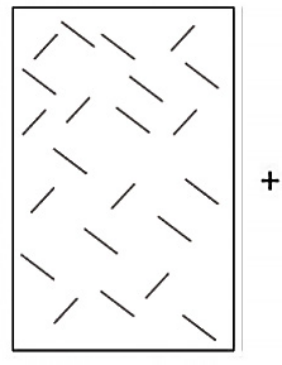

FIBRA

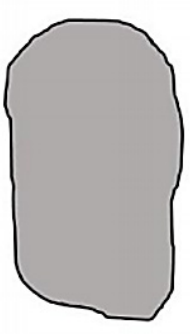

MATRIZ

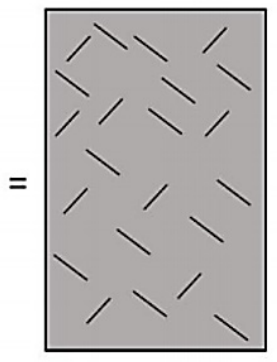

COMPÓSITO
Figura 1: Representação da formação de material compósito reforçado por fibras Fonte: elaborada pelo autor com base em Kreutz, 2020.

Podem ser classificados como: naturais ou híbridos. Entre os naturais podem ser citados: a madeira ou o osso constituinte de um organismo vivo. Já entre os híbridos, esses podem ser produzidos sobre duas formas, reforçados por partículas ou por fibras, naturais ou sintéticas. A matriz, por sua vez, pode ser composta por material metálico, cerâmico ou polimérico. Proporciona a forma estrutural ao material, transferindo o esforço mecânico para o reforço. Além disso, a matriz também isola as fibras ou partículas permitindo que cada fibra ou partícula possa agir isoladamente evitando assim a propagação de trincas, além de melhorar o acabamento superficial (KREUTZ, 2020).

\section{FIBRAS DE COCO}

Provenientes do coqueiro conhecido como coco-da-baía no Brasil, as fibras de coco são protetoras da amêndoa nucifera. Entre os vegetais do agronegócio destaca-se com importância socioeconômica na produção de água de coco ou albúmen para as indústrias de alimentos e cosméticos e gera grande quantidade de resíduos. (NUNES, 2009).

Na literatura, desde os estudos de Nunes (2009), o Brasil já era produtor anual de 1.116.969.000 frutos obtendo como subproduto cascas e fibras do coco. Porém, o aproveitamento de seus resíduos no Brasil ainda é modesto apesar de suas inúmeras potencialidades de uso, podendo ter vários destinos como: produção de paineis, geração de energia, substrato agrícola, artesanato, entre outros (ARAÚJO et al., 2018).
Em 2017, a porção nacional aproveitada de fibras de coco foi da ordem de 7 mil toneladas, em relação a uma parcela de 753 mil toneladas de cocos cultivada no país. Na produção mundial do fruto, conforme os dados da Organização da Agricultura e Alimentos, o Brasil aparece na $5^{\circ}$ posição no ranking, sendo superado apenas pela Indonésia, Filipinas, Índia e Sri Lanka (IBGE, 2018); (FAO 2018).

Existem três tipos de fibras: fibra branca longa, fibra marrom longa e fibra marrom curta. A fibra branca é extraída da casca do coco-verde com 8 a 10 meses de idade; é mais fina, mais longa e mais macia do que a fibra marrom. A fibra marrom longa pode ser fina ou grossa. As fibras marrons são extraídas de cocos maduros com aproximadamente 12 meses de idade. Cerca de um terço do material fibroso é constituído de fibras longas, e dois terços, de fibras curtas (NUNES, 2009).

\subsection{Caracterização da Fibra de Coco}

Advinda do fruto "coco" que possui formato ovalado com cerca de $30 \mathrm{~cm}$ de comprimento e em torno de $25 \mathrm{~cm}$ de diâmetro, conforme a ilustração na Figura 2, onde apresenta o epicarpo sendo a camada mais externa fina e lisa, o mesocarpo áspero e fibroso e o endocarpo bastante rígido, com uma grande cavidade central que contém a água do fruto. A casca (epicarpo) está associada ao mesocarpo de 3 a $5 \mathrm{~cm}$ de espessura, de onde se extraem as fibras do coco (REDDY; YANG, 2015).

Possuem alto teor de lignina como polímero de união das fibras celulósicas que aumenta a rigidez protegendo contra o ataque de microrganismos. Nesse sentido, apresentam-se como boas alternativas na produção de paineis. Estão entre as fibras lignocelulósicas são as que contêm o menor teor de celulose pura, e por isso, não se apresentam adequadas à indústria do papel. (DAMASCENO FILHO, 2018).

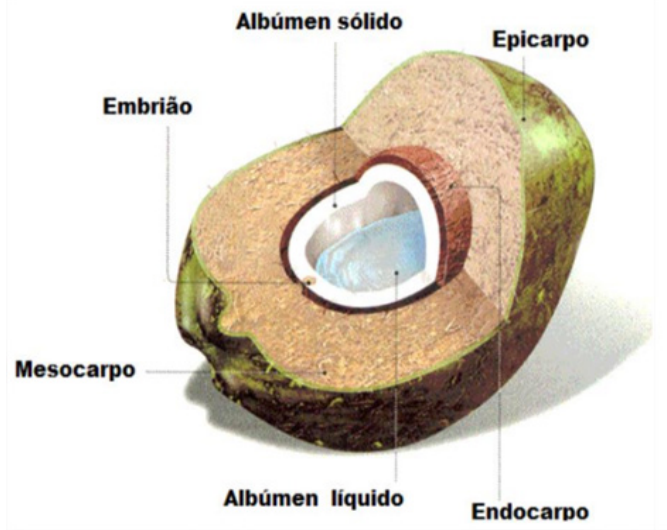

Figura 2: Estrutura do coco Fonte: Mattos et al. 2011. 


\subsection{Obtenção e classificação da fibra de coco}

Pouco se evoluiu em relação aos processos para a obtenção das fibras do coco. No Brasil, foram implantadas as primeiras unidades desfibradoras mecanizadas a partir da década de trinta. O processo inicia-se com a separação da casca do resto do fruto por meio de uma lâmina oval ou de máquina. Separadas as cascas, elas são submetidas à maceração, que consiste na imersão em água para a desagregação dos tecidos fibrosos. Tradicionalmente, são usados tanques ou reservatórios naturais de água (WIEDMAN, 2002).

A estrutura para a obtenção da fibra do coco é realizada por meio de um maquinário composto por prensa rotativa para a retirada de líquidos e outra para classificação e separação da fibra e do pó. Desta forma, com a extração desta umidade, possibilita também a retirada de sais para a seleção do material e adequação quanto ao nível de salinidade do pó obtido no processo (DE SOUZA et al., 2015).

A máquina selecionadora é equipada com um rolo de facas fixas e uma chapa perfurada. Nela o material é turbiIhonado ao longo do seu eixo, fazendo com que o pó caia pela chapa perfurada e o restante do material continue o percurso. A casca é constituída por uma fração de fibras e outra denominada de pó. Como dito anteriormente, as fibras de coco são obtidas basicamente do mesocarpo e caracterizam-se pela sua dureza e durabilidade atribuída ao alto teor de lignina. Esse material apresenta baixa taxa de degradação, levando mais de 8 a 12 anos para completa decomposição in natura (DE SOUZA et al., 2015).

As fibras de coco podem ser classificadas em três tipos: "Fibras de fiação", os fios possuem formatos mais longos e finos, comumente são empregadas na indústria têxtil; "Fibras de escovas", são mais curtas e grosseiras em relação às fibras de fiação, normalmente usadas em escovas pincéis e as "Fibras de estofamento", entre os três tipos são as mais curtas e aproveitadas como material de preenchimento e na produção de compósitos (DAMASCENO FILHO, 2018).

\subsection{Propriedades físico-químicas da fibra do coco}

$\mathrm{Na}$ estrutura do coco nucifera, as fibras do epicarpo e endocarpo possuem alto poder de impermeabilização diferentemente das fibras constituintes do mesocarpo. $E$ as fibras do mesocarpo possuem além de resistência ao apodrecimento, elasticidade considerável, podendo alongar-se até $50 \%$ do seu tamanho sem se romper (SAVASTANO et al., 1997).

Além disso, apresentam baixa densidade, boa maleabilidade, alta porosidade, são inodoras, resistente à umidade, não são atacadas por roedores, não produzem fungos, tem condutividade térmica baixa, portanto, são considerados materiais isolantes, térmico e acústico. Por possuir um percentual de celulose mediano e grande concentração de lignina, cerca de duas a quatro vezes os valores existentes em fibras como a juta e o sisal, as fibras de coco apresentam um melhor comportamento térmico em relação às demais (SENHORAS, 2003).

No quadro 1 abaixo, está apresentado um resumo das propriedades físico-químicas da fibra de coco.

\begin{tabular}{|l|l|}
\hline PROPRIEDADE & PARÂMETRO \\
\hline Massa Específica real $\left(\mathrm{kg} / \mathrm{m}^{3}\right)$ & 1.177 \\
\hline Alongamento na ruptura (\%) & 23,9 a 51,4 \\
\hline Resistência à tração (MPa) & 95 a 118 \\
\hline Módulo de elasticidade (GPa) & 2,8 \\
\hline Condutividade Térmica (W/mk) & 0,043 a 0,045 \\
\hline Comportamento ao fogo & Classe B2 \\
\hline pH & 5,4 \\
\hline Densidade (g/L) & 70 \\
\hline Porosidade (\%) & 95,6 \\
\hline Retenção de água (ml/L) & 538 \\
\hline Lignina (\%) & 35 a 45 \\
\hline Celulose (\%) & 23 a 43 \\
\hline
\end{tabular}

Quadro 1: Propriedades do Cocos nucifera Fonte: Savastano et al., 1997; Senhoras, 2003.

As fibras de coco apresentam propriedades físico-químicas adequadas para confecção de chapas para isolamento termoacústico, com alto ganho energético com refrigeração e redução de níveis sonoros de impacto e aéreos por possuir capacidade de absorver baixas frequências, além da resistência à degradação biológica (DE SOUZA et al., 2015).

\section{ADESIVOS APLICÁVEIS NA PRODUÇÃO DE COMPÓSITOS DE FIBRAS DE COCO}

Os adesivos são polímeros formulados com endurecedores, normalmente a base de formaldeídos, que quando misturados transformam-se em um produto único de características irreversíveis (termorrígidos). Podem ser naturais de origem animal, vegetal ou com derivados de petróleo, como no caso dos acrílicos. Entre eles, os mais utilizados na indústria madeireira para a produção de compósitos destacam-se os de origem petroquímica, predominantemente à base dos bicomponentes: uréia-formaldeído (UF); fenol-formaldeído (FF); a melamina-formaldeído; o resorcinol-formaldeído; os adesivos termoplásticos como o polivinil-acetato (PVA), e, em menor escala, os adesivos de tanino vegetal (CARVALHO, A. G. et al., 2016). 
Além desses, entre os polímeros utilizados em matrizes de compósitos (reforçados por dispersão de partículas) estão: o polimetil-meta-acrilato (PMMA); os poliuretanos (PU); a poliolefina termoplástica (TPO); o siloxano oligomérico (POSS) e as resinas, epóxi e fenólica. Em todas as opções, para que os adesivos se demonstrem eficientes, alguns pontos devem ser levados em consideração como: o coeficiente de expansão térmica dos materiais a serem colados; a relação de $\mathrm{pH}$ para que não ocorra o ataque químico indesejável na peça a ser colada; a resistência mecânica; a resistência térmica; a resistência a fadiga do material, e o tempo de vida da peça em condições ambientais diversas (RENDA et al., 2015).

\subsection{Classificação dos adesivos}

Existem diferentes classificações para os adesivos destinados à colagem de produtos similares. A classificação desses adesivos pode ser baseada na resistência à umidade e suas temperaturas de cura (CARVALHO et al., 2016).

A classificação quanto à resistência à umidade se resume em ser à prova ou não d'água. Já a classificação por temperatura fundamenta-se em relação à cura dos adesivos e é dividida em três categorias sendo elas: alta (superiores a $90^{\circ} \mathrm{C}$ ), média (entre 30 e $90^{\circ} \mathrm{C}$ ) e baixa (temperaturas abaixo de $30^{\circ} \mathrm{C}$ ) (DE MENDOZA, 2017).

Entre os adesivos resinosos existem aqueles que são classificados como termofixos ou termorrígidos, que são os polímeros resistentes a altas temperaturas, mantendo-se indeformáveis e outros que são termoplásticos. Os materiais termoplásticos tendem a tornarem-se fluidos quando aquecidos e apresentam potencial capacidade de liberação de gases tóxicos quando ultrapassados suas temperaturas críticas (DE MENDOZA et al., 2017).

\subsection{Bioadesivos compatíveis com compósitos de fibras vegetais}

As bioresinas referem-se a qualquer tipo de resina que tenha em sua formulação ao menos um componente de origem vegetal atuando como substituto de substância similar de origem petroquímica. Entre elas: polilactatos; poliésteres alifáticos-aromáticos; poliuretanas a partir de óleos vegetais; poliamidas via proteína de mamona e bioresinas (DE SOUZA SILVA et al., 2019).

De acordo com os estudos de Wiedman (2002), entre elas têm sido utilizadas as bioresinas fenólicas na produção de compósitos, desenvolvendo-se produtos diversos, além daqueles voltados para a construção civil. No caso da produção de prensados a partir da fibra do coco, pode-se utilizar basicamente as seguintes resinas: o Líquido da Castanha do Caju (LCC); a poliuretana de óleo de mamona (PU) e o tanino.
O LCC foi desenvolvido pela "Aglodeste" (Aglomerados do Nordeste Ltda), uma das empresas que fazem parte da incubadora PADETEC da Universidade Federal do Ceará. Outra opção é a resina poliuretana de óleo de mamona obtida a partir do óleo extraído de sementes de mamona (Ricinus communis). As resinas PU usadas como aglomerantes para revestimentos poliméricos são do tipo elastoméricas e, em seu estado endurecido, têm características de borracha dura. Na construção civil, a resina poliuretana (PU) de óleo de mamona se apresenta como alternativa a materiais betuminosos na impermeabilização de lajes (SILVA et al., 2018).

No Brasil, o adesivo de tanino é comercializado pela empresa "Tanac S.A." que, atualmente, é a única a produzir a bioresina no país e está localizada em Montenegro, a $60 \mathrm{~km}$ de Porto Alegre/RS. A produção de tanino se dá a partir da casca da Acácia Negra. A empresa, desde sua fundação, a partir de 1984, passou também a produzir adesivos para madeira que apresentam custo, em média, 15 a 20\% inferior à resina fenólica sintética. Além disso, apresenta pH entre 6,6 a 6,9, ou seja, próximos da neutralidade, o que quimicamente indica baixa reatividade com outras substâncias (TANAC, 2020).

Os taninos são compostos fenólicos biodegradáveis com capacidade de formar complexos proteicos e estão presentes na forma hidrolisada e condensada em cascas, folhas e frutos. Destaca-se como fonte mais comum de taninos, principalmente no Brasil, a Acácia Negra, vegetal responsável por mais de $90 \%$ da produção mundial de tanino. Essa substância é solúvel em diversos solventes, tais como álcool, éter, acetona e água. Além disso, o tanino pode reagir com formol, resultando em uma resina termorrígida, como a ilustrada na Figura 3 (PALEARI, 2014).

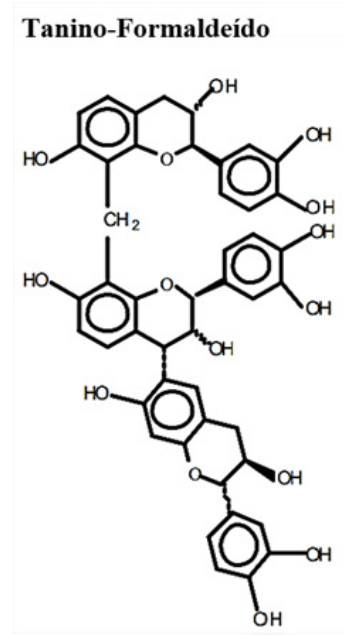

Figura 3: representação química do adesivo à base de tanino-formaldeído Fonte: TANAC, 2020. 
Os taninos são compostos fenólicos biodegradáveis com capacidade de formar complexos proteicos e estão presentes na forma hidrolisada e condensada em cascas, folhas e frutos. Destaca-se como fonte mais comum de taninos, principalmente no Brasil, a Acácia Negra, vegetal responsável por mais de $90 \%$ da produção mundial de tanino (PALEARI, 2014).

Segundo Wiendman (2002), o uso do adesivo com formaldeído resulta em uma chapa menos suscetível ao inchamento do que com as resinas UF, devido à sua constituição química com estruturas polifenólicas de cadeias hidrofóbicas reduzindo esse risco.

\section{RESÍDUOS PLÁSTICOS}

Os resíduos plásticos são materiais poliméricos recicláveis que representam mais de $80 \%$ do total de materiais poliméricos consumidos no mundo e possuem propriedades que possibilitam diferentes aplicações em setores produtivos como os da: construção civil, da automotiva, de embalagens, entre outros. Nesta seção objetiva-se apresentar uma breve visão sobre os resíduos plásticos com ênfase nos termoplásticos destacando-se entre eles o polietileno de alta densidade (PEAD). (JAÉN, 2019).

Os termoplásticos tornam-se fluidos quando submetidos a uma temperatura acima do "ponto de amolecimento", o que possibilita que esses sejam refundidos diversas vezes. Em contrapartida, os termofixos permanecem com sua rigidez inalterada com a temperatura, permitindo sua fusão apenas uma vez (ASSOCIAÇÃO BRASILEIRA DA INDÚSTRIA DO PLÁSTICO, 2018).

Possuem resistências consideráveis ao impacto, são bons isolantes térmicos e de baixo custo. A reciclagem desses materiais está relacionada à separação que depende da classificação e eliminação das impurezas, podendo ser realizada de maneira manual ou automática. Para facilitar a triagem do material a ser reciclado, a norma NBR 13230 padroniza os símbolos que identificam cada tipo de plástico. A Figura 4 ilustra os símbolos adotados pela ABNT para os tipos de plásticos, facilitando a sua separação.

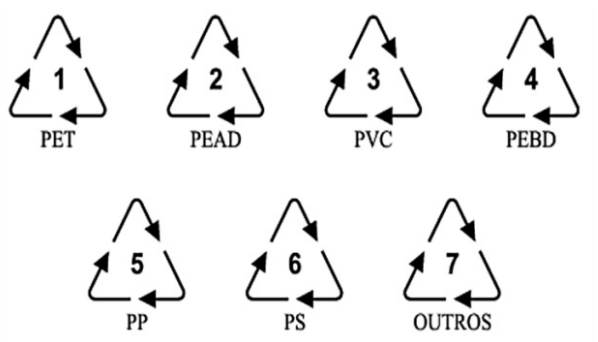

Figura 4: Símbolos utilizados para materiais plásticos em processos de reciclagem Fonte: ABNT, 2008.
Na figura acima cada numeração corresponde a uma sigla:

1 - PET (tereftalato de polietileno)

2 - PEAD (polietileno de alta densidade)

3 - PVC (Policloreto de Vinila)

4 - PEBD (Polietileno de baixa densidade)

5 - PP (Polipropileno)

6 - PS (poliestireno)

7 - Outros plásticos.

A reciclagem é "um processo de transformação dos resíduos sólidos que envolve a alteração de suas propriedades físicas ou químicas, com vistas à transformação em insumos ou novos produtos..." (Brasil, 2010). E segundo AlSalem et al., (2010) os processos de reciclagem dos plásticos podem ser classificados em quatro categorias:

a) primária; conhecida como reciclagem mecânica ou física, diferenciando-se apenas pela origem dos resíduos plásticos a serem reciclados, pós industrial na primária e pós-consumo na secundária (SPINACÉ; PAOLI, 2005).

b) secundária; caracterizada pelo reprocessamento dos plásticos pós-consumo por meios mecânicos, para a sua posterior utilização na fabricação de produtos (AL-SALEM et al., 2010).

c) terciária que também é conhecida como reciclagem química, os resíduos plásticos são convertidos em pequenas moléculas, como óleos, hidrocarbonetos e monômeros, adequados como matéria-prima para produção de novos plásticos.

d) quaternária ou de reaproveitamento de energia que consiste na queima do resíduo a fim de se obter energia em forma de calor, vapor e eletricidade (ALSALEM et al., 2010).

No caso do processo de recuperação energética, seja por meio da incineração ou por métodos termoquímicos, ambos contribuem para a redução no volume de resíduos, porém alguns polímeros que contêm cloro e flúor, por exemplo, podem causar problemas durante a combustão devido a emissão de $\mathrm{HCl}$ (cloreto de hidrogênio) ou HF (fluoreto de hidrogênio) e dioxinas (SPINACÉ; PAOLI, 2005).

Existem formas distintas de se reciclar os resíduos plásticos. O processo de reciclagem depende das condições específicas do material e da viabilidade técnica, econômica e ambiental. Contudo, destaca-se a reciclagem mecânica como a mais vantajosa do ponto de vista industrial por apresentar menor custo, por ser mais confiável e pelo grande volume de resíduos plásticos pós-consumo disponíveis (HAMAD et al., 2013). 


\subsection{Polietileno de alta densidade (PEAD)}

Segundo Faria (2002), um dos grandes problemas de reciclagem dos materiais poliméricos relaciona-se ao descarte de tais produtos como as poliolefinas (PEAD, PEBD e PP) para reciclagem do material. Esses resíduos poliméricos industriais são relativamente fáceis de reciclar porque a sua contaminação geralmente é insignificante e quando aquecidos, podem ser fundidos formando um compósito resistente inclusive à intensa radiação solar.

Para a seleção dos termoplásticos utilizaram-se basicamente os critérios do ponto de fusão abaixo de $200^{\circ}$ $C$, pois acima desta temperatura os materiais podem apresentar instabilidade química liberando gases tóxicos (JAÉN, 2019).

Entre os termoplásticos apresentados, o de interesse do presente artigo é o PEAD por ser abundante, de fácil reciclagem, baixa reatividade e boa resistência mecânica mesmo quando exposto a radiação solar. No Quadro 2 a seguir, apresentam-se os dados característicos do polietileno de alta densidade.

\begin{tabular}{|l|l|}
\hline PROPRIEDADES & VALOR \\
\hline Ponto de Fusão $\left({ }^{\circ} \mathrm{C}\right)$ & 130 \\
\hline Temperatura Max. de processamento $\left({ }^{\circ} \mathrm{C}\right)$ & 210 \\
\hline Condutividade térmica $(\mathrm{W} / \mathrm{m} . \mathrm{K})$ & 0,37 \\
\hline Densidade média $\left(\mathrm{g} / \mathrm{cm}^{3}\right)$ & 0,96 \\
\hline Limite de resistência à tração $(\mathrm{MPa})$ & 16,8 \\
\hline Tensão de escoamento sob tração $(\mathrm{MPa})$ & 24,9 \\
\hline Tensão de esc. sob compressão $(\mathrm{Mpa})$ & 21,3 \\
\hline Módulo de elasticidade à tração $(\mathrm{MPa})$ & 880 \\
\hline
\end{tabular}

Quadro 2: Propriedades básicas do PEAD

Fonte: Faria, 2002.

De acordo com Faria (2002), as propriedades mecânicas do PEAD reciclados são muito próximas às propriedades do material virgem tendo a vantagem de custar em média metade do valor do material. Além disso, o PEAD constitui um termoplástico com boas propriedades para associação aos compósitos de fibras vegetais, principalmente usando o processo de prensagem.

\section{PARÂMETROS FÍSICO-QUÍMICOS DOS MA- TERIAIS DE ANÁLISE}

Nesta seção são demonstrados os dados relativos aos parâmetros físico-químicos para comparação e análise da compatibilidade dos materiais de estudo: fibras de coco; adesivo de tanino e resíduos de PEAD. Entre os dados anteriormente demonstrados nos quadros 1 e 2 , destacam-se relevantes, a temperatura como parâmetro físico e o pH como químico.
Basicamente para a produção de um produto como o idealizado neste estudo (telha em camadas) é necessário saber se a temperatura de cura do adesivo escolhido é compatível com o material de reforço (fibras de coco). Trata-se da averiguação de compatibilidade de temperaturas de trabalho de materiais diferentes. $O$ tanino foi considerado por além de ser um bioadesivo, atualmente é o único disponível no mercado nacional.

No quadro 3 apresentam-se as temperaturas úteis de trabalho desses materiais. Tratam-se das temperaturas em que os materiais deverão encontra-se ao mesmo tempo em situação de alta temperatura.

\begin{tabular}{|l|l|l|l|}
\hline Componentes & $\begin{array}{l}\text { Ponto de } \\
\text { Ignição Médio } \\
\left({ }^{\circ} \mathbf{C}\right) \text { em pres- } \\
\text { são ambiente }\end{array}$ & $\begin{array}{l}\text { Temperatura } \\
\text { de Cura }\left({ }^{\circ} \mathbf{C}\right) \\
\text { a } 25 \text { kgf } / \mathbf{c m}^{2} \\
\text { e 15 } \mathbf{~} / \mathbf{~ m m}\end{array}$ & $\begin{array}{l}\text { Temperatura } \\
\text { de molda- } \\
\text { gem }\left({ }^{\circ} \mathbf{C}\right)\end{array}$ \\
\hline PEAD & 350 & 20 a 80 & 160 a 190 \\
\hline Fibras de Coco & 200 a 210 & ------ & ------ \\
\hline Adesivo de tanino & 520 a 530 & 150 a 160 & ------ \\
\hline
\end{tabular}

Quadro 3: Faixas de temperaturas dos materiais analisados Fonte: Adaptado de Lira et al., 2014.

Comparando os pontos de ignição dos três componentes pode-se estabelecer uma temperatura de compatibilização para que não ocorra a degradação dos materiais.

Em relação ao parâmetro de temperatura, de acordo com o quadro 3, a faixa de valores de produção do material compósito pode ocorrer em torno de $150^{\circ} \mathrm{C}$ a $160^{\circ} \mathrm{C}$, visto que as fibras de coco podem resistir a temperaturas superiores a essa faixa. Já para a temperatura de trabalho para o reuso dos resíduos de $P E A D$, percebe-se a faixa de $160^{\circ} \mathrm{C}$ a $190^{\circ} \mathrm{C}$ sem comprometer as propriedades do material plástico.

Com relação ao parâmetro químico $\mathrm{pH}$, sabe-se que materiais com $\mathrm{pHs}$ diferentes tendem a reagir. Sabe-se que o PEAD exibe baixa reatividade química e o adesivo de tanino, conforme boletim técnico Tanac, possui faixa de $\mathrm{pH}$ em torno de 6,6 a 6,9. Dessa forma comparando esses valores de $\mathrm{pH}$ com o das fibras de coco, no quadro 1 , verifica-se que a associação desses materiais é quimicamente possível uma vez que não ocorrerá reação, ou seja, um material não terá ação corrosiva sobre o outro.

\section{CONSIDERAÇÕES FINAIS}

Com a os dados obtidos da literatura e da comparação dos parâmetros físico-químicos de temperatura e $\mathrm{pH}$, verificou-se a viabilidade técnica de compatibilização dos resíduos do coco e PEAD para a produção de uma telha em camadas com propriedades de isolamento térmico e acústico vindas das fibras de coco. 
A partir do que foi demonstrado nas pesquisas publicadas até o presente momento, outro ponto revelado com a comparação desses parâmetros foi à demonstração da viabilidade técnica de produção de um compósito de fibras de coco com uma resina de origem vegetal.

Além disso, verificou-se a possibilidade da aplicação de outros tipos de bioadesivos, contudo seus parâmetros físico-químicos não foram levantados nesta pesquisa por não estarem disponíveis no mercado seguidos de seus respectivos boletins técnicos.

Acerca do polímero escolhido para o estudo, verificou-se que o PEAD se demonstra com uso potencial, visto a sua abundância no Brasil de forma de residual e de simples reciclagem.

Por fim, conclui-se que no Brasil, o gerenciamento de resíduos sólidos ainda se encontra distante do desejável. Todos os resíduos analisados se encontram visíveis por onde quer que se caminhe, muitas vezes, lamentavelmente descartados no meio ambiente de modo ilegal.

\section{REFERÊNCIAS}

AL-SALEM, S.M; LETTIERI, P; BAEYENS, J. The valorization of plastic solid waste (PSW) by primary to quaternary routes: from re-use to energy and chemicals.

Progress in Energy and Combustion Science, [S.I.], v. 36, p. 103-129, 2010.

ARAÚJO JR, C.P.A.; COAQUIRA, C.A.C.; MATTOS, A.L.A.; SOUZA, M.D.S. M.; Andrade Feitosa, J.P.; MORAES, J.P.S.; ROSA Rosa, M.F. Binderless fiberboards made from unripe coconut husks. Waste and Biomass Valorization, v.9, n.11, p.2245-2254, 2018.

ASSOCIAÇÃO BRASILEIRA DA INDÚSTRIA DO PLÁSTICO - ABIPLAST. Perfil 2018 - Indústria Brasileira de Transformação de Material Plástico. Disponível em: <http://www.abiplast.org.br/wp-content/uploads/2019/10/perfil2018-web_VC.pdf>. Acesso em: 23 mai. 2020.

ASSOCIAÇÃO BRASILEIRA DE NORMAS TÉCNICAS. ABNT NBR 13230. Embalagens e acondicionamento plásticos recicláveis - Identificação e simbologia. São Paulo, 2008.

BRASIL. Lei no 12.305/2010, de 02 de agosto de 2010. Política Nacional de Resíduos Sólidos, 2010. Disponível em <http://www.planalto.gov.br/ccivil_03/_ato20072010/2010/lei/l12305.htm>. Acesso em: 23 mai. 2020.

CARNEIRO, L.P. Obsolescência planejada e suas implicações no âmbito do Direito Ambiental e do Consumidor. Direito-Araranguá, 2018.

CARVALHO, A.G. et al. Adesivos naturais e sintéticos em painéis compensados. Revista Ciência da Madeira (Brazilian Journal of Wood Science), v. 7, n. 1, 2016. COCO VERDE, disponível em:<http://www.cocoverderj.com.br/imprensa/Setor-Reciclagem-ProjetoCoco-Verde-RJ.htm>. Acessado em: 22 mai. 2020.

DAMASCENO FILHO, F.E. Utilização da fibra de coco como proposta de substituição de cimento em tijolos ecológicos de solo-cimento: uma análise físico-mecânica. Trabalho monográfico. Universidade Federal Rural do Semi-Árido, 2018.

DA SILVA et al. Reaproveitamento sustentável dos resíduos da noz macadâmia. 2018. Disponível em: <http:// www.revistaea.org/artigo.php?idartigo $=3377>$. Acesso em: 17 jun. 2020.

DE ASSIS PASSOS, P.R. Destinação sustentável de cascas de coco (Cocos nucifera) verde: obtenção de telhas e chapas de partículas. Tese de Doutorado. Universidade Federal do Rio de Janeiro, 2005.

DE MENDOZA et al. Aspectos gerais sobre adesivos para madeira. Multitemas, v. 22, n. 51, 2017.

DE SOUZA SILVA, B. P. et al. PRODUÇÃO DE ADESIVO A PARTIR DA LIGNINA RESIDUAL DE PROCESSO INDUSTRIAL. In: MOCCIF19-4a Edição da Mostra Científica e Cultural do IFSP Suzano. 2019.

DE SOUZA, E.S. et al. Aplicação da fibra de coco no processo de isolamento termo acústico. Revista Gestão \& Sustentabilidade Ambiental, v. 4, p. 233-245, 2015. FAO STAT. Food and Agriculture Organization of the United Nations. World Production. 2018. Disponível em: $\quad<$ http://www.fao.org/faostat/es/\#data/GA>. Acessado em: 11 mai. 2020.

FARIA, A.C.A. Análise macromecânica de compósitos poliméricos reciclados. 134f. Dissertação de mestrado. DEMEC/UFMG, Belo Horizonte, 2002.

IBGE/LSPA. Instituto Brasileiro de Geografia e Estatística. Levantamento Sistemático da Produção Agrícola. (2018). Disponível em: <https://sidra.ibge. gov.br/tabela/6588\#resultado>. Acesso em: 02 abri. 2020.

ISOMIL: Catálogo do fabricante. Disponível em: <https://www.isomil.com.br/fabrica-telhas-sanduiche-rj>. Acesso em: 29 mai. 2020

JAÉN, M.; ESTEVE, P.; BANOS-GONZÁLEZ, I. Los futuros maestros ante el problema de la contaminación de los mares por plásticos y el consumo. Revista Eureka sobre Enseñanza y Divulgación de las Ciencias, n. 16, v. 1, p. 1501-1517, 2019.

KOTIK, H.G. Fibras naturais e compósitos reforçados com fibras naturais: a motivação para sua pesquisa $e$ 
desenvolvimento. Matéria (Rio de Janeiro), v. 24, n. 3, 2019.

KREUTZ, J.C. et al. Propriedades mecânicas e térmicas de compósitos de poliestireno e MDF. Dissertação de Mestrado. Universidade Estadual do Oeste do Paraná. 2019.

LIRA, J.O.B; SILVA, K.C.G da; ANDERSEN, S..LF. Estudo das características de combustão de resíduos sólidos da região nordeste utilizando análise termogravimétrica. In: XX Congresso Brasileiro de Engenharia Química. Anais. 2014.

MATTOS, A.L.A. et al. Beneficiamento da casca do coco verde. Fortaleza: Embrapa Agroindústria Tropical, 2011. 37 p. Disponível em: <http://www. ceinfo.cnpat.embrapa.br/arquivos/artigo_3830.pdf>. Acesso em: 21 mai. 2020.

NAKAMURA, A.P.D. Propriedades de painel biocompósito produzido com fibras de coco-da-baía e ácido cítrico como adesivo. 2018.

NUNES, M.U.C; DOS SANTOS, J.R. Alternativas tecnológicas para o aproveitamento de resíduos de coquerio gigante para produção de adubo orgânico, compostagem e outras. Embrapa Tabuleiros Costeiros - Capítulo em livro científico (ALICE), 2009. Disponível em: <https://www. agencia.cnptia.embrapa.br/gestor/coco/arvore/ CONT000giw3qz5o02wx5ok05vadr1u5iye30.html\#>. Acesso em: 17 mai. 2020.

PALEARI, T.H. Coagulantes naturais e coagulante químico para o tratamento de efluente de indústria de café solúvel. Trabalho de Conclusão de Curso, do Curso Superior de Engenharia Ambiental da Universidade Tecnológica Federal do Paraná. Campus Londrina, 2014.

PASSOS, P.R.A. Destinação sustentável de cascas de coco (cocos nucifera) verde: Obtenção de telhas e chapas de partículas. COPPE/UFRJ. Rio de Janeiro, 2005. Disponível em: <http://www.ppe.ufrj.br/ppe/ production/tesis/ppassos.pdf $>$. Acesso em: 20 abr. 2020.

PEREIRA, E.V. Resíduos sólidos. Editora Senac, São Paulo, 2019.

RENDA, C.G. et al. Estudo da resina fenólica fenol/ formaldeído e sua aplicação como matriz na preparação de nanocompósitos poliméricos contendo nanotubos de carbono. 2015.

SAVASTANO JR., H.; NOLASCO, A.M.; OLIVEIRA, L. Disponibilidade de resíduos de alguns tipos de fibra vegetal, no Brasil, para uso em componentes de construção. In: SEMINARIO IBEROAMERICANO 1997 DE MATERIALES COMPUESTOS FIBRORREFORZADOS, 1., y REUNION PROYECTO PIP VIII.5 CYTED, 3., Santiago de Cali, mai. 1997. Memorias. Santiago de Cali, Universidad del Valle/Cyted, 1997. p.128-32.

SENHORAS, E. Estratégia de uma Agenda para a Cadeia Agroindustrial do Coco. Campinas: Ed. ESC, 2003.

SILVA, E.J. da et al. Compósito cimentício com elevado teor de fibra de coco tratada: propriedades físicas e durabilidade. Matéria (Rio de Janeiro), v. 23, n. 3, p.1-19, 2018.

COLEN, A.G.N. et al. Rotas tecnológicas empregadas no aproveitamento de resíduos da indústria da soja. Revista Brasileira de Energias Renováveis, v. 8, n. 1, p. 326-363, 2019.

SPINACÉ, M.A. da; PAOLI, M.A. de. A tecnologia da reciclagem de polímeros. Química Nova, [S.I], v. 28, n. 1, p. 65-72, 2005.

TANAC S.A. Disponível em: <http://www.tanac.com. br/pt-br/produtos/especialidades $>$. Acesso em: 25 abr. 2020.

WIEDMAN, G.A. Fibra de coco e resinas de origem vegetal para produção de componentes de mobiliário e da construção civil. Tese de doutorado. Universidade de São Paulo, 2002. 


\section{AUTORES}

ORCID: https://orcid.org/0000-0002-0727-1431

MÁRCIOARAÚJODESOUZA,M.Sc.|USISUAM-CentroUniversitário Augusto Motta | Programa de Pós-Graduação em Desenvolvimento Local do Centro Universitário Augusto Motta, UNISUAM, Rio de Janeiro, RJ.| e-mail: marcimaraujodesouza@gmail.com

ORCID: https://orcid.org/0000-0003-3484-145X

LUCIO Fá́BIO CASSIANO NASCIMENTO, Dr. | Pesquisador do Programa de Pós-Graduação em Desenvolvimento Local do Centro Universitário Augusto Motta, UNISUAM, Rio de Janeiro, RJ. | e-mail: lucionascimento@souunisuam.com. br

ORCID: http://orcid.org/0000-0002-7883-9442

Kátia ELIANE SANTOS AVELAR, Dra. | Pesquisadora do Programa de Pós-Graduação em Desenvolvimento Local do Centro Universitário Augusto Motta, UNISUAM, Rio de Janeiro, RJ. Correspondência para: Programa de Pós-Graduação em Desenvolvimento Local. Avenida Paris, 84, Bonsucesso, Rio de Janeiro, RJ, Brasil. CEP: 21.041-020| e-mail: katia. avelar@gmail.com

\section{COMO CITAR ESTE ARTIGO}

SOUZA, Márcio Araujo de; NASCIMENTO, Lucio Fábio Cassiano; AVELAR, Kátia Eliane Santos. Análise De Viabilidade De Produção De Cobertura Ecológica A Partir De Resíduos Sólidos. MIX Sustentável, [S.I.], v. 7, n. 2, p. 105-114, abr. 2021. ISSN 24473073. Disponível em:<http://www.nexos.ufsc.br/index.php/ mixsustentavel>. Acesso em: dia mês. ano. doi:https:// doi.org/10.29183/2447-3073.MIX2021.v7.n2.105-114. 